\title{
Assessment of the Suitability of Paper Waste as an Engineering Material
}

\author{
Oriyomi M. Okeyinka \\ Department of Civil Engineering, Faculty of Technology, \\ University of Ibadan \\ Ibadan, Nigeria \\ oriyomiokeyinka@yahoo.com
}

\author{
Oluwatobi J. Idowu \\ Department of Civil Engineering, Faculty of Technology, \\ University of Ibadan \\ Ibadan, Nigeria \\ idowuoluwatobijohn@yahoo.com
}

\begin{abstract}
This research work investigates the potential applicability of waste paper in the production of ceiling boards with focus on achieving: environmental sustainability, safe disposal of waste paper and more cost effective production of materials. The main view was to provide an alternative to the conventional asbestos ceiling boards that are costly and also pose health risks. Three mix designs were formulated and used for the casting (1:1, 1:1.5 and 1:2), varying in regards of the weight of the waste paper components. $\mathrm{CaCO}_{3}$ was added to the mix as an additive as well as starch bond glue to aid binding. Laboratory experiments were conducted to determine the properties and suitability of the produced boards. Properties such as water absorption, abrasion, compressive strength, flexural strength and ultimate loads were considered for comparison. The boards with 1:1 mix ratio displayed the best results of the test properties hence, its mechanized manufacturing was recommended.
\end{abstract}

Keywords- waste paper; ceiling board; compressive strenght; water absorption.

\section{INTRODUCTION}

Managing waste is one of the greatest challenges for human societies, as various human activities result to the production of significant amounts of waste of different kinds. The term waste describes the unneeded byproducts (materials) produced during the production of a certain product or the product itself after a certain time span. Waste has usually nothing to contribute to the environment other than pollution. The reuse of waste materials is a waste minimization strategy which includes reclaiming activities [1, 2]. Waste materials can be used directly or recycled to produce the same or another product. This has the benefit of not only reducing the amount of waste material but can also provide significant cost reduction for the production of new materials [3-4].

Solid waste is of most interest is, as it is the most frequently occurring of all waste types as it occurs from individual or domestic, industrial and agricultural activities. Especially domestic wastes tend to pile up and their management is a task of significant importance for advanced cultures. Recycling is a good approach to waste reduction, but it has been reported that during recycling, a $40 \%$ of the wastes to be recycled are proved to be non-recyclable, (i.e. a lot of these wastes still remain in the waste stream) [3]. In an attempt to counter this problem, waste is adopted as raw materials for the production of other materials.

Paper seems to be the most common as it is involved in many areas such as stationeries, cartons for packaging, disseminating news to people and many more. Paper is an example of valuable materials that can be recycled. Disposable paper available in abundance throughout the world is composed mainly of short, natural, cellulose fibers and is already used in many local raw materials. Waste paper comes from various sources such as newspapers, office and printing papers etc. Each has a different type of fiber quality, and mixing all these papers of different qualities will reduce the purity of the highest quality fiber. The quality of the waste determines the end quality of the recycled paper. Therefore, an investigation concerning the potential of the different re-pulped waste paper types as construction materials is essential in order to gain an insight into their behavior and properties [5].

Various researchers have shown that waste paper may be useful in construction materials such as concrete, solid blocks and ceiling boards and also can act as insulators in buildings. A hollow concrete block using recycled paper waste has been constructed and the result was similar to using expanded slate as an aggregate [6]. The response of recycled paper waste concrete has been studied in [7] and concluded that it has much softer response to higher damping and energy absorption. The eco-friendly parameter was underlined in [8]. The use of waste paper as constituent materials in plastering mortar was considered in [9] and it was shown that it enables the utilization of non-polluting technology with low energy consumption. Therefore, the use of waste paper in building materials could solve problems concerning the quality and affordability of building materials and simultaneously ameliorate the associated environmental concerns.

This paper targets at producing ceiling boards with waste newspaper. The mix ratio are presented along with the integrity of the final product, considering various different parameters. 


\section{EXPERIMENTAL PROCEDURE}

\section{A. Materials}

The materials used for the experimentation include waste newspaper, cement, gum and $\mathrm{CaCO} 3$. The cement used was an ordinary Portland cement (Elephant cement) produced by the West African Portland Cement Ewekoro, and certified by the British Standard Specification (BS 12) [10]. Old newspapers newsprint were obtained from large offices, hotels and nearby markets. These papers are with organic composition greater than $95 \%$ and inorganic composition of less than $5 \%$. It was soaked in water for softening and was ground thoroughly to form paper slurry with little water present. The $\mathrm{CaCO}_{3}$ used was finely ground with equivalent particle sizes smaller than 2 $\mathrm{mm}$. It was mixed with water and the undissolved part of it was removed.

\section{B. Preparation and Casting of Board}

The shredded newspapers were soaked into hot water for two days to allow for adequate softening and thereafter grounded thoroughly to form a slurry. This ground paper material was dewatered with the use of a hydraulic jack. It was left for a day ( $24 \mathrm{hrs}$ ) for proper dewatering. Three replicates of the boards were produced, at 1:1, 1:1.5 and 1:2, cement paper ratio respectively. On each replicate sample, constant quantities of $\mathrm{CaCO}_{3}$ and gum were added without varying. The watercement ratio used was 1.0:0.50 and $150 \mathrm{~g}$ of $\mathrm{CaCO}_{3}$ and $150 \mathrm{~g}$ of starch was used for each of the samples. Then the materials were poured and thoroughly mixed together and then poured into the formwork of dimension $400 \mathrm{~mm} \times 400 \mathrm{~mm} \times 15 \mathrm{~mm}$, where adequate compaction and smoothening was ensured. The formworks were removed after $24 \mathrm{hrs}$ and the boards were cured for 14 days to attain the necessary strength. The necessary tests were thereafter conducted.

\section{Test Procedures}

Tests which considered abrasion, flexural and compressive strength, water absorption rate, density, modulus of elasticity, modulus of rupture were carried out on the boards and the procedures used are described below.

\section{1) Abrassion Test}

For the purpose of this test, a dried sample of the board was weighed $\left(\mathrm{W}_{1}\right)$. A hard shoe brush was used to rub against the two surfaces of the board. 50 strokes of forward and backward movements each were made against the surfaces. The flaked particles from the surfaces were collected and weighed. The flaked board was also weighed $\left(\mathrm{W}_{2}\right)$. This procedure was repeated for nine more samples. Flaking concentration $(\mathrm{Fc})$ was determined using the expression in (1):

$$
\mathrm{Fc}=\frac{\mathrm{W}_{1}-\mathrm{W}_{2}}{\mathrm{~W}_{1}}
$$

\section{2) Flexural and Compressive Strength Test}

These tests were conducted at the Federal Institute of Industrial Research, Oshodi (FIIRO) in Lagos State of Nigeria. They were carried out using a testometric machine. The flexural test shows the ability of the boards to resist shearing; the maximum force that can cause the board to fail flexurally was recorded and plotted against the deflection. The compressive test shows the ability of the boards to resist compression. The load intensity was increased gradually and the responding compressions of the boards at each load variation were noted.

\section{3) Water Absorption Rate Test}

The dry boards were weighed and immersed in water for 24 hours. They were allowed to surface-dry then weighed. Water absorption was calculated using:

$$
\mathrm{p}=\frac{\left(\mathrm{W}_{\mathrm{s}}-\mathrm{W}_{\mathrm{d}}\right)}{\mathrm{W}_{\mathrm{d}}} \cdot 100(\%)
$$

where $\mathrm{p}$ is the percentage water absorption, $\mathrm{W}_{\mathrm{s}}$ is the weight of the surface-dry sample and $\mathrm{W}_{\mathrm{d}}$ is the weight of dry sample

\section{4) Modulus of Elasticity}

This is the measure of resistance of the board to bending or flexure, (it is related to the stiffness of the board).This was calculated on the boards from the data supplied in the flexural test by using the formula:

$$
\mathrm{MOE}=\frac{23 \cdot \mathrm{P} \cdot \mathrm{L}^{3}}{648 \cdot \mathrm{I} \cdot \delta}
$$

where $\mathrm{P}=$ the applied load or force on the board, $\mathrm{L}=$ length of the board; $\mathrm{I}=$ moment of inertia $=\mathrm{bh}^{3} / 12$ where $\mathrm{b}$ and $\mathrm{h}$ are the width and thickness of the board respectively and $\delta=$ deflection on the board.

\section{5) Modulus of Rupture}

This is to determine the peak load the board can carry, it is calculated with the formula

$$
\mathrm{MOR}=\frac{\mathrm{P} \cdot \mathrm{L}}{6} \cdot \frac{\mathrm{c}}{1}
$$

All parameters remain the same as above and $\mathrm{c}=$ half thickness of the board

\section{RESULT AND DISCUSSIONS}

\section{A. Properties of the Board}

The results of compressive strength test, flaking/abrasion, water absorption and density check conducted on the board samples are summarized and presented in Table I and Figures $1-3$

\section{1) Density}

The average densities of the boards are presented in Table I. Mix 1:2 was found to be the densest of the board samples. This can be attributed to the quantity of waste paper it contains. The volume of each of the test board sample was $2.25 \times 10^{-4} \mathrm{~m}^{3}$ calculated from the product of the length, width and thickness which are $150 \mathrm{~mm}, 150 \mathrm{~mm}$ and $15 \mathrm{~mm}$ respectively.

\section{2) Compressive Strength}

The result here shows that the compressive strength increases with the increase in cement content. Increase in proportion of paper pulp to cement leads to brittleness. 


\section{3) Flaking/Abrassion}

The mean values of the abrasion obtained from the experimental board samples ranged from $0.69 \%$ to $1.23 \%$. This shows that the ceiling boards with the higher quantity of newspaper pulp are prone to flaking.

\section{4) Water Absorption}

Out of the three samples tested for water absorption, It was found that sample A with the mix ratio of 1:1 absorbed the least quantity of water and its percentage water absorptivity was $17 \%$ unlike samples $\mathrm{B}$ and $\mathrm{C}$ of mix ratio $1: 1.5$ and $1: 2$ respectively which in turn showed a percentage water absorptivity to be $19.8 \%$ and $30.7 \%$ respectively. Based on the results shown, it is noted that the mixing proportion has significant effect on the water absorption. This shows that more water is absorbed with increasing quantity of paper pulp. Hence, there is a need for pretreatment of paper to be used in ceiling boards in order to to reduce its affinity for water.

TABLE I. PROPERTIES OF THE BOARD PRODUCED FROM THREE DIFFERENT MIXES

\begin{tabular}{|c|c|c|c|c|c|}
\hline 兽 & : & 承 & 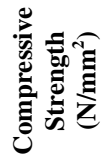 & 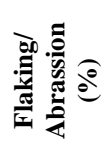 & 党 \\
\hline$A$ & $1: 1$ & 91.11 & 13.50 & 0.69 & 17.00 \\
\hline B & $1: 1.5$ & 147.56 & 9.00 & 1.11 & 19.80 \\
\hline $\mathrm{C}$ & $1: 2$ & 184.89 & 7.59 & 1.23 & 30.70 \\
\hline
\end{tabular}

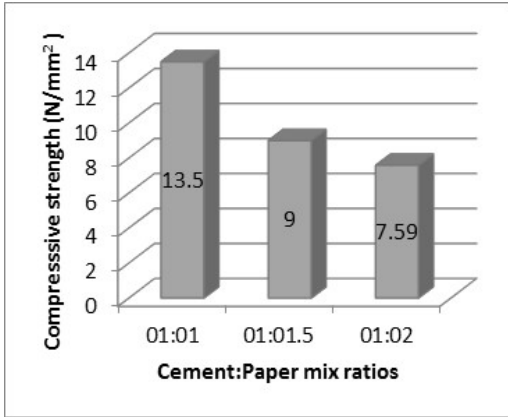

Fig. 1. Compressive strength of boards made with different cement/paper mix ratios

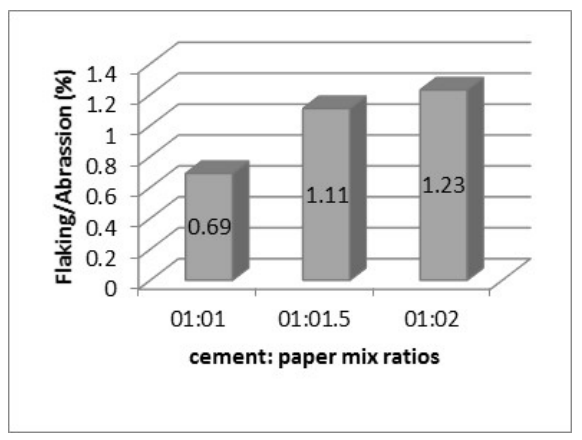

Fig. 2. Flaking/Abrasion properties of boards made with different cement/ paper mix ratios.

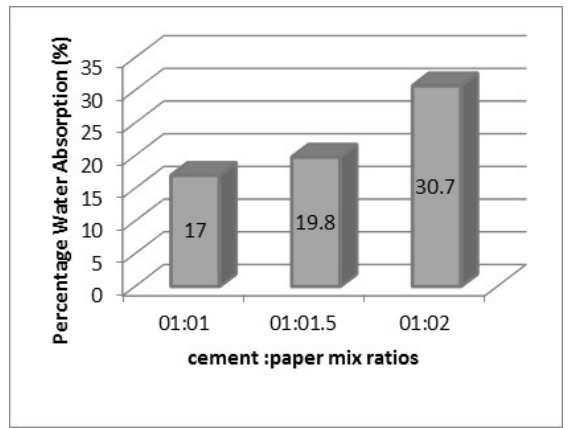

Fig. 3. Water absorption properties of boards made with different cement/ paper mix ratios.

\section{B. Mechanical Properties of the Board}

The mechanical properties in terms of flexural strength, MOR and MOE are summarized in Table II. Figure 4 shows the load deflection curve for the three board samples.

\section{1) Flexural Strength}

The highest flexural strength value $0.31 \mathrm{~N} / \mathrm{mm}^{2}$ was achieved on the board sample with mix ratio $1: 1$. Other values are $0.25 \mathrm{~N} / \mathrm{mm}^{2}$ and $0.18 \mathrm{~N} / \mathrm{mm}^{2}$ for samples produced from mixes $1: 1.5$ and $1: 2$ respectively. It was found that sample $A$ failed on the application of more than $15 \mathrm{~N}$ load, sample B failed after the load applied was more than $10 \mathrm{~N}$ and sample $\mathrm{C}$ failed on the application of load more than $6 \mathrm{~N}$.

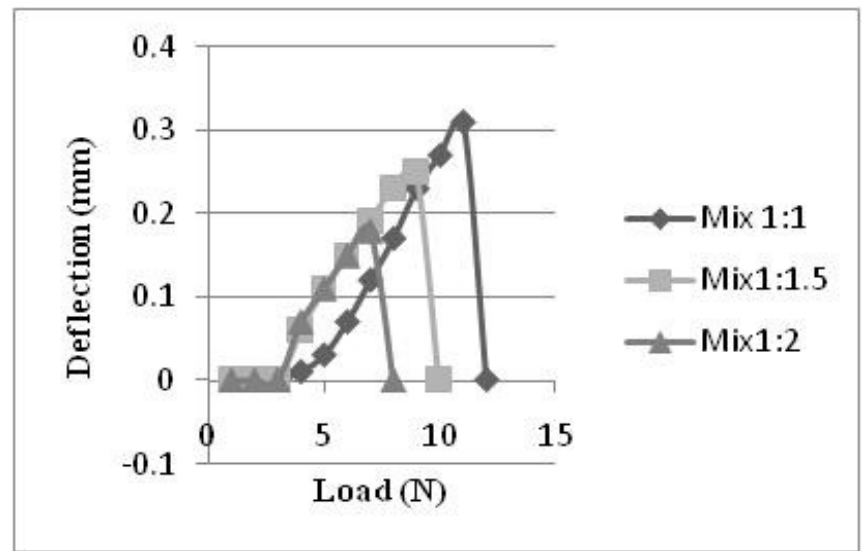

Fig. 4. Load deflection curves for boards made with different cement/paper mix ratio.

\section{2) Modulus of Elasticity and Modulus of Rupture}

The results of the flexural strength test were used to compute both the MOE and the MOR of the boards. Having obtain the thickness, $\mathrm{h}$ of the board $=15 \mathrm{~mm}$, Length of the samples $=150 \mathrm{~mm}, \mathrm{c}=$ half of thickness $=\mathrm{h} / 2=7.5 \mathrm{~mm}$, width, $\mathrm{b}$ of the samples $=100 \mathrm{~mm}$. Hence $\mathrm{I}=\mathrm{bh}^{3} / 12=28125 \mathrm{~mm}^{4}$. Therefore, from the values of MOR and MOE presented in Table II, it can be seen that the maximum MOR is $0.1 \mathrm{~N} / \mathrm{mm}^{2}$ which is satisfactory with the ASTM 208-72 requirement of not exceeding $2 \mathrm{~N} / \mathrm{mm}^{2}$. 
TABLE II. SUMMARY OF FLEXURAL STRENGTH AND MECHANICAL PROPERTIES OF THE BOARDS

\begin{tabular}{|c|c|c|c|c|c|c|c|c|c|}
\hline & \multicolumn{3}{|c|}{ Mix 1:1 } & \multicolumn{3}{c|}{ Mix 1:1.5 } & \multicolumn{3}{c|}{ Mix 1:2 } \\
\hline $\begin{array}{c}\text { Load } \\
(\mathbf{N})\end{array}$ & $\begin{array}{c}\text { Deflection } \\
(\mathbf{m m})\end{array}$ & $\begin{array}{c}\text { MOR } \\
\left(\mathbf{N} / \mathbf{m m}^{2}\right)\end{array}$ & $\begin{array}{c}\text { MOE } \\
\left(\mathbf{N} / \mathbf{m m}^{2}\right)\end{array}$ & $\begin{array}{l}\text { Deflection } \\
(\mathbf{m m})\end{array}$ & $\begin{array}{c}\text { MOR } \\
\left(\mathbf{N} / \mathbf{m m}^{2}\right)\end{array}$ & $\begin{array}{c}\text { MOE } \\
\left(\mathbf{N} / \mathbf{m m}^{2}\right)\end{array}$ & $\begin{array}{c}\text { Deflection } \\
(\mathbf{m m})\end{array}$ & $\begin{array}{c}\text { MOR } \\
\left(\mathbf{N} / \mathbf{m m}^{2}\right)\end{array}$ & $\begin{array}{c}\text { MOE } \\
\left(\mathbf{N} / \mathbf{m m}^{2}\right)\end{array}$ \\
\hline 0 & 0.00 & 0.00 & 0.00 & 0.00 & 0.00 & 0.00 & 0.00 & 0.00 & 0.00 \\
\hline 1 & 0.01 & 0.01 & 0.43 & 0.06 & 0.01 & 0.07 & 0.07 & 0.08 & 0.06 \\
\hline 2 & 0.03 & 0.02 & 0.43 & 0.11 & 0.13 & 0.08 & 0.11 & 0.01 & 0.08 \\
\hline 4 & 0.07 & 0.03 & 0.30 & 0.15 & 0.03 & 0.11 & 0.15 & 0.03 & 0.11 \\
\hline 6 & 0.12 & 0.05 & 0.25 & 0.19 & 0.04 & 0.14 & 0.18 & 0.04 & 0.14 \\
\hline 8 & 0.17 & 0.06 & 0.23 & 0.23 & 0.05 & 0.15 & failure & & \\
\hline 10 & 0.23 & 0.07 & 0.20 & 0.25 & 0.07 & 0.17 & & & \\
\hline 13 & 0.27 & 0.09 & 0.20 & failure & & & & & \\
\hline 15 & 0.31 & 0.1 & 0.20 & & & & & & \\
\hline 17 & failure & & & & & & & & \\
\hline
\end{tabular}

\section{CONCLUSIONS}

Based on the results of this work, the following conclusions can be drawn:

- old newsprint paper fibers had significant effects on the mechanical and physical properties of the composites.

- as the paper fiber content is increased, significant increase in water absorption occurs.

- the optimum condition was obtained at cement paper ratio 1:1. Further increase in paper fiber content results in lower strength properties

- However, the result of MOR was satisfactory based on the ASTM 208-72 standard requirement.

- The use of $\mathrm{CaCO} 3$ also contributes to less water absorption. The overall water absorption of the three samples, appears to be lower compared to boards made with other admixtures in previous research.

\section{REFERENCES}

[1] H. S. Peavy, D. R Rowe, G. Tchobanoglou, Environmental engineering, McGraw-Hill, 1984

[2] R. L. Schroeder, "The use of recycled materials in highway construction", Public Roads, Vol. 58, No. 2, 1994, available at: https://www.fhwa.dot.gov/publications/publicroads/94fall/p94au32.cfm

[3] VicRoads, "Recycled materials in pavement construction", 2014

[4] A. O. Ibhadode, Environmental pollution: causes, effects and solutions, Ambik Press, Nigeria, 2004

[5] V. Sangrutsamee, Panya Srichandr, Nuchthana Poolthong, "Re-pulped waste paper-based composite building materials with low thermal conductivity", Journal of Asian Architecture and Building Engineering, Vol. 11, pp. 147-151, 2012

[6] S. Modry, "Use of Waste Paper as a Constituent of Concrete" in Recovery and recycling of paper international symposium, Thomas Telford Publishing, United Kingdom, pp. 77-80, 2001

[7] J. D. Decard, R. P. West, S. J. Prichard, "The impact response of recycled paper waste concrete", in Recovery and recycling of paper international symposium, Thomas Telford Publishing, United Kingdom, pp. 81-92, 2001

[8] J. S. Manuel, "How do paper houses stack up?", Journal on Environmental Health Perspective, Vol. 3, No. 110, p. 126, 2002

[9] C. Aciu, D. A. Ilutiu-Varvara, N. Cobirzan, A. Balog, "Recycling of Paper Waste in the composition of plastering mortars", Procedia Technology, Vol. 12, pp. 295-300, 2014
[10] British Standard Institute, Specification for Portland cement, 1991

[11] B. C. Tobias, "Fabrication and Performance of Natural Fiber-Reinforced Composite Materials", 35th International SAMPE Symposium, pp. 970978, 1990

APPENDIX

\begin{tabular}{|c|c|}
\hline Symbols & Meaning \\
\hline MOE & Modulus of elasticity \\
\hline MOR & Modulus of rupture \\
\hline P & Thplied load or force acting on the board \\
\hline h & Percentage water absorption \\
\hline p & Length of board samples \\
\hline L & Width of board samples \\
\hline b & Moment of Inertia \\
\hline I & Half of thickness of board samples \\
\hline c & Deflection of board samples \\
\hline$\delta$ & Weight of dry board samples \\
\hline $\mathrm{W}_{1}$ & Weight of flaked board samples \\
\hline $\mathrm{W}_{2}$ & Weight of surface dried board samples \\
\hline $\mathrm{W}_{\mathrm{s}}$ & Weight of dry board samples \\
\hline $\mathrm{W}_{\mathrm{d}}$ & \\
\hline
\end{tabular}

